\title{
PENGGUNAAN PARAMETER BARU POTENSIAL WOODS - SAXON UNTUK PERHITUNGAN SPEKTRUM TENAGA INTI ${ }^{208} \mathrm{~Pb}$
}

\author{
Raden Oktova \\ Program Magister Pendidikan Fisika, Universitas Ahmad Dahlan, Yogyakarta \\ Kampus II, J1.Pramuka 42, Yogyakarta 55161 \\ E-mail: pasca.pfisika@yahoo.com
}

\begin{abstract}
ABSTRAK
PENGGUNAAN PARAMETRISASI BARU POTENSIAL WOODS-SAXON UNTUK PERHITUNGAN SPEKTRUM TENAGA INTI ${ }^{208} \mathrm{~Pb}$. Telah dihitung aras-aras tenaga partikel-tunggal dan lubang-tunggal untuk inti ${ }^{208} \mathrm{~Pb}$ menggunakan potensial Woods - Saxon dengan parametrisasi baru dalam ruang koordinat dengan algoritma Numerov. Dibandingkan parametrisasi lama, parametrisasi baru potensial Woods-Saxon berhasil meningkatkan ketelitian deviasi rms tenaga terhadap eksperimen hanya sejauh menyangkut deviasi rms tenaga partikel-tunggal saja, namun gagal untuk deviasi rms (root mean square) tenaga lubang-tunggal. Dalam hal struktur aras tenaga, parametrisasi baru justru menunjukkan lebih banyak kesalahan urutan aras daripada parametrisasi lama.
\end{abstract}

Kata kunci: aras tenaga partikel-tunggal, aras tenaga lubang-tunggal, ${ }^{208} \mathrm{~Pb}$, potensial Woods-Saxon, algoritma Numerov

\section{ABSTRACT}

APPLICATION OF A NEW PARAMETRIZATION OF TIE WOODS-SAXON POTENTIAL TO THE CALCULATION OF ENERGY SPECTRUM IN ${ }^{208} \mathrm{~Pb}$. Single-particle and single-hole energy levels in the nucleus ${ }^{208} \mathrm{~Pb}$ are calculated using a new parametrization of the Woods-Saxon potential in coordinate space and the Numerov algorithm. The application of the new parameter set proves to be capable of improving the accuracy of the calculation compared to a previous parameter set as measured from the energy standard deviation (relative to the experimenial values) only for single-particle levels, but it fails completely for single-hole levels. In the level structure, the new parameter set shows even more level misorder than the old.

Keywords: single-particle energy levels, single-hole energy levels, 208Pb, Woods-Saxon potential, Numerov algorithm

\section{PENDAHULUAN}

Deskripsi masalah banyak-benda inti (nuclear many-body problem) dengan suatu potensial rata-rata efektif atau potensial partikel-tunggal merupakan terobosan dalam fisika inti. Dalam model kulit untuk inti ini, dinamika sebuah nukleon ditentukan oleh medan rata-rata yang diakibatkan oleh semua nukleon lain dalam inti, dan pemilihan himpunan keadaan dasar partikel-tunggal yang tepat merupakan kunci ketelitian. Data inti seperti bilangan-bilangan ajaib, jari-jari inti, tenaga ikat inti, kelimpahan inti di alam dan berbagai besaran dalam reaksi inti memperkuat gambaran model medan ratarata yang sangat sederhana ini ${ }^{[1]}$. Dalam sejarah fisika inti, potensial partikel-tunggal osilator harmonik dengan koreksi spin-orbit merupakan model potensial partikel-tunggal pertama yang berhasil meramalkan urutan orbital dan bilangan ajaib [2]. Untuk 
mondeskripsikan inti secara teliti, parameterparameter osilator dipilih dengan kcbergantungan tertentu pada nomor massa inti, dan rumus yang banyak dipakai adalah $\hbar \omega=41 \mathrm{~A}^{1 / 3} \mathrm{MeV}$, yang diperoleh dengan membandingkan jari-jari rms massa osilator dengan data eksperimental. Persamaan Schrödinger-nya dapat diselesaikan dalam bentuk analitis eigenfungsi keadaan dasar partikel-tunggal, namun di sisi lain gaya-gaya sisa partikel-partikel menjadi besar, walaupun ada juga perhitungan-perhitungan cukup mutakhir dengan model ini yang berhasil mendiagonalisasi Hamiltonian banyak-benda termasuk gaya sisa partikel-partikel secara tepat $^{[j-4]}$. Kajian fisika inti saat ini telah mencapai daerah inti jauh di luar daerah kestabilan di mana daerah kontinu (continuum) spektrum medan partikel-tunggal menjadi penting. Untuk itu, potensial partikel-tunggal Woods-Saxon $^{[5]}$ banyak digunakan. Memang penyelesaiannya tidak lagi analitis namun dapat dihasilkan daerah kontinu spektrum, dan kehadiran komputer canggih saat ini memungkinkan penyelesaian numerik menjadi jauh lcbih mudah; selain itu bentuk potensialnya realistik karena menyerupai distribusi kerapatan inti. Sejumlah parametrisasi potensial Woods-Saxon telah dilakukan orang, dengan tujuan yang berbedabeda dan bcrlaku untuk daerah massa inti yang berbeda-beda pula. Motivasi ini diperkuat dengan munculnya data-data baru aras-aras tenaga partikel-tunggal inti-inti bola ${ }^{[6-7]}$.

Dalam kerangka pemikiran inilah penulis dalam kajian scbelumnya telah mengkaji ketelitian penggunaan potensial Woods-Saxon untuk menghitung aras-aras partikel-tunggal nukleon inti-inti bola, yaitu ${ }^{16} \mathrm{O},{ }^{40} \mathrm{Ca},{ }^{48} \mathrm{Ca}{ }^{[8]}$, dan ${ }^{208} \mathrm{~Pb}^{[9]}$, dengan menggunakan parametrisasi Shlomo dan Bertsch ${ }^{[10]}$ yang disempurnakan oleh Bertsch ${ }^{[11]}$. Dalam perkembangan terkini, Schwierz dkk. ${ }^{[12]}$ telah mendapatkan himpunan parameter baru untuk potensial Woods-Saxon yang diyakini merupakan himpunan parameter global, dan memenuhi prinsip-prinsip simetri kekekalan isospin dalam gaya inti serta kinematika duabenda. Dalam parametrisasi baru ini digunakan himpunan aras partikel-tunggal (single-particle states) dan lubang-tunggal (single-hole states) di sekitar inti-inti ajaib-rangkap ${ }^{16} \mathrm{O},{ }^{40} \mathrm{Ca},{ }^{48} \mathrm{Ca}$, ${ }^{56} \mathrm{Ni},{ }^{100} \mathrm{Sn},{ }^{132} \mathrm{Sn}$ dan ${ }^{208} \mathrm{~Pb}$ sebagai data acuan eksperimental untuk melakukan pencocokan kuadrat terkecil. Makalah ini menyajikan hasil penggunaan himpunan parameter baru potensial Woods-Saxon tersebut untuk menghitung spektrum tenaga partikel-tunggal dan lubang-tunggal inti bola, dan inti ajaibrangkap ${ }^{208} \mathrm{~Pb}$ diambil sebagai contoh karena data eksperimental lengkap spektrum tenaga partikel-tunggal dan lubang-tunggal yang cukup mutakhir tersedia ${ }^{[13-14]}$.

\section{TEORI}

Sebenarnya dalam parametrisasi barunya, Schwierz dkk. ${ }^{[12]}$ mendeskripsikan potensial Woods-Saxon dengan pendekatan yang sedikit berbeda, namun tidak jauh berbeda dengan yang disajikan penulis dalam kajian-kajian sebelumnya ${ }^{[8-9]}$, potensial partikcl-tunggal Woods-Saxon secara lengkap dapat disajikan dalam tiga suku, yakni potensial sentral berupa fungsi Fermi $\left(V_{S W}\right)$ dengan koreksi kopling spin-orbit $\left(V_{s}\right)$ dan potensial Coulomb $\left(V_{c}\right)$ yang dinyatakan dalam Pers. (1),

$$
V=V_{S W}+V_{s}+V_{C},
$$

dengan

$$
\begin{gathered}
V_{S W}=\frac{-V_{0}}{1+e^{\frac{r-R}{a}}}, \\
V_{C}=V_{C}(r)-\frac{2 V_{T}(A-2 Z-1)}{A\left(1+e^{\frac{r-R}{a}}\right)}, \\
V_{s}=f_{\ell} V_{s o} \frac{e^{\left(r-R_{s}\right) i a_{s}}}{a_{s} R_{s}\left(1+e^{\left(r-R_{s}\right) \cdot a_{s}}\right)^{2}} .
\end{gathered}
$$

Dalam potensial Coulomb Pers. (3) menjadi

$$
V_{C}(r)= \begin{cases}\frac{Z k e^{2}}{R_{c}}\left[1,5-0,5\left(\frac{r}{R_{c}}\right)^{2}\right], & r<R \\ \frac{Z k e^{2}}{r}, & r \geq R,\end{cases}
$$

dan $k$ konstanta gava statik Coulomb. Dalam suku spin-orbit Pers. (4), dapat ditulis

$$
f_{\ell}=\left\{\begin{array}{l}
\ell \quad \text { bila } 2 \ell<j \\
-(\ell+1) \text { bila } 2 \ell \geq j
\end{array}\right.
$$

dengan $\ell$ bilangan kuantum momentum sudut orbital dan $j$ bilangan kuantum momentum sudut total. 
Berdasarkan parametrisasi Shlomo dan Bertsch ${ }^{[0-11]}$ yang digunakan penulis dalam kajian sebelumnya, nilai-nilai parameter dalam Pers. (2-4) adalah

$$
\begin{aligned}
& V_{0}=53+V_{T}\left(\frac{A-2 Z-1}{A}\right) \mathrm{MeV}, \\
& R=R_{s}=1,25(A-1)^{1 / 3} \mathrm{fm}, \\
& a=a_{s}=0,65 \mathrm{fm}, \\
& V_{T}=20 \mathrm{MeV} \\
& V_{s a}=-15,5 \mathrm{MeV}
\end{aligned}
$$

Jadi parameter jari-jari dan kekaburan (diffuseness) sumur tidak dibedakan, $R=R_{s}$ dan $a=a_{s}$. Dalam parametrisasi baru, nilainilai parameter adalah

$$
\begin{aligned}
& V_{0}=52,06+V_{T}\left(\frac{A-2 Z-1}{A}\right) \mathrm{MeV}, \\
& R=1,26 A^{1 / 3} \mathrm{fm}, \\
& R_{s}=1,16 A^{1 / 3} \mathrm{fm}, \\
& a=a_{s}=0,662 \mathrm{fm}, \\
& V_{s o}=-24,1 \mathrm{MeV} .
\end{aligned}
$$

Adapun $V_{T}=20 \mathrm{MeV}$, sama dengan parameter scbelumnya. Terdapat koreksi pusat massa inti dalam parametrisasi baru sehingga digunakan massa tereduksi sistem inti

$$
\mu=\frac{m M}{m+M},
$$

dengan $m$ massa nukleon, dan $M$ massa sisa inti dianggap $M=(A-1)$ sama. Dalam kajian ini, massa tereduksi dihampiri dengan massa nukleon.

Dalam koordinat bola, persamaan Schrödinger untuk potensial Woods-Saxon (1) dapat ditulis

$$
\left(-\frac{h^{2}}{2 m} \nabla^{2}+V\right) \Psi(r, \theta, \phi)=E \Psi(r, \theta, \varphi) \text {. }
$$

Aras-aras tenaga partikel-tunggal nukleon adalah eigennilai tenaga, $E$ pada pers. (10). Dengan metode pemisahan variabel, dimisalkan

$$
\Psi(r, \theta, \phi)=R(r) \Theta(\theta) \Phi(\phi),
$$

dan dengan substitusi $U=R r$, maka persamaan bagian radial menjadi

$$
-\frac{h^{2}}{2 m} \frac{d^{2} U}{d r^{2}}+\left(V+\frac{\ell(\ell+1) \hbar^{2}}{2 m r^{2}}\right) U=E U
$$

atau

$$
\frac{d^{2} U}{d r^{2}}=F(r, U)
$$

dengan

$$
F(r, U)=\left(\frac{2 m}{\hbar^{2}}(V-E)+\frac{\ell(\ell+1)}{r^{2}}\right) U,
$$

artinya diferensial kedua $U$ terhadap $r$ hanya bergantung pada variabel bebas $r$ dan $U$ yang dicari serta tidak mengandung $d U / d r$, sehingga persamaan diferensial dapat diselesaikan dengan algoritma Numerov.

\section{METODE PENYELESAIAY NUMERIK}

Penyelesaian secara numerik pers. (14) dengan algoritma Numerov dapat dilakukan dengan hampiran [15]

$$
U_{I+1} \approx\left\{2-\frac{m \Delta^{2}}{\hbar^{2}}\left(V-E+\frac{\ell(\ell+1) \hbar^{2}}{2 m r^{2}}\right)\right\} U_{i}-U_{t-1} .
$$

dengan $\Delta r$ adalah lebar langkah antara dua titik kisi berurutan. Jika dianggap $r$ sangat kecil dibandingkan seluruh jangkauan $r$, maka berlaku hampiran

$$
U(r)=r^{i+1},
$$

dengan demikian untuk lebar langkah $\Delta r=0,1$ misalnya, nilai $U$ pada dua titik pertama dapat dihampiri dengan

$$
U_{1} \approx 0,1^{\prime+1}, \quad U_{2} \approx 0,2^{i+1} .
$$

Selanjutnya aras-aras tenaga partikel-tunggal, $E$ dapat dihitung dengan langkah-langkah sebagaimana diuraikan dalam [8-9].

Untuk membantu perhitungan numerik, dibuat sebuah program perhitungan dalam bahasa Windows Compaq Visual Fortran Professional Edition 6.5.0 yang diberi nama SW dengan mengembangkan subrutin STATIC, yaitu subrutin perhitungan aras-aras tcnaga partikel-tunggal dan eigenfungsi dari potensial Woods-Saxon yang merupakan bagian dari program RPA3 ${ }^{[10-11]}$. Masukan program adalah nomor atom dan nomor massa inti, serta orbital-orbital partikel-tunggal dan lubangtunggal osilator harmonik isotrop ${ }^{[5]}$ berdasarkan urutan seperti pada Tabel 1. 
Parameter-parameter kisi yang digunakan sama scperti pada kajian sebelumnya, yaitu cacah titik kisi sama dengan 50, dan lebar langkah $\Delta r=0,25 \mathrm{fm}$. Untuk tebakan awal eigennilai tenaga digunakan batas atas nol dan batas bawah $-50 \mathrm{MeV}$.

\begin{tabular}{|c|c|c|c|}
\hline 0 & $3 / 2$ & 00 & $1 s$ \\
\hline 1 & $5 / 2$ & 01 & $1 p$ \\
\hline 2 & $7 / 2$ & 10,02 & $2 s, 1 d$ \\
\hline 3 & $9 / 2$ & 11,03 & $2 p, 1 f$ \\
\hline 4 & $11 / 2$ & $20,12,04$ & $3 s, 2 d, 1 g$ \\
\hline 5 & $13 / 2$ & $21,13,05$ & $3 p, 2 f, 1 h$ \\
\hline 6 & $15 / 2$ & $30,22,14,06$ & $4 s, 3 d, 2 g, 1 i$ \\
\hline 7 & $17 / 2$ & $31,23,15,07$ & $4 \mathrm{p}, 3 \mathrm{f}, 2 \mathrm{~h}, 1 \mathrm{j}$ \\
\hline
\end{tabular}

Perhitungan aras-aras tenaga partikel-tunggal dan lubang-tunggal dengan potensial WoodsSaxon parametrisasi lama oleh Shlomo dan Bertsch [10-11] merujuk pada himpunan parameter Pers. (7), sedangkan parametrisasi baru merujuk pada himpunan parameter Persamaan (8).

\section{HASIL DAN PEMBAHASAN}

Hasil perhitungan aras-aras tenaga partikeltunggal dan lubang-tunggal dalam inti $208 \mathrm{~Pb}$ dengan potensial Woods-Saxon disajikan pada Tabel 2 untuk neutron dan Tabel 3 untuk proton, dan untuk mudahnya hanya disajikan nilai mutlak tenaga (yang sebenarnya bernilai negatif). Skema aras-aras tenaga disajikan dalam Gambar 1 dan 2. Aras-aras lubangtunggal disajikan dengan huruf tebal dan data eksperimental disajikan dengan tanda bintang. Pada Gambar 1 dan Gambar 2 batas antara aras-aras partikel-tunggal dan lubang-tunggal ditunjukkan oleh bilangan ajaib 126 untuk neutron dan 82 untuk proton. Nilai eksperimental diambil dari ${ }^{[13]}$ untuk partikeltunggal, dan dari ${ }^{[14]}$ untuk lubang-tunggal. Sebagai perbandingan digunakan hasil perhitungan swakonsisten Fayans dkk. ${ }^{[17]}$ yang sejauh ini tampaknya merupakan perhitungan paling teliti untuk spektrum tenaga inti ${ }^{209} \mathrm{~Pb}$, dengan deviasi rms tenaga terhitung terhadap nilai eksperimental sebesar $0,580 \mathrm{MeV}$ untuk neutron dan $0,286 \mathrm{McV}$ untuk proton.

Hasil perhitungan dengan potensial Woods-Saxon parametrisasi lama memberikan tenaga yang umumnya lebih tinggi dari nilai eksperimental, sedangkan hasil perhitungan dengan potensial Woods-Saxon parametrisasi baru memberikan tenaga yang tersebar di sckitar nilai eksperimental.

Tabel 2. Hasil perhitungan aras-aras tenaga partikcl-tunggal dan lubangtunggal neutron, dinyatakan dengan $-E$ dalam satuan $\mathrm{MeV}$

\begin{tabular}{|c|c|c|c|c|}
\hline \multirow{2}{*}{ Aras } & \multirow{2}{*}{ Fayans dkk. } & \multicolumn{2}{|c|}{ Woods-Saxon } & \multirow{2}{*}{ Eksp. } \\
\hline & & Lama & Baru & \\
\hline $1 \mathrm{~h}_{9 / 2}$ & 10,304 & 13,95 & 8,83 & 10,85 \\
\hline $2 \mathrm{f}_{7 / 2}$ & 10,959 & 13,13 & 11,56 & 9,72 \\
\hline $1 \mathbf{i}_{13 / 2}$ & 9,178 & 11,18 & 11,77 & 9,01 \\
\hline $2 \mathrm{f}_{5 / 2}$ & 8.540 & 10,79 & 7,56 & 7,95 \\
\hline $3 p_{3 / 2}$ & 8,540 & 10,85 & 8,90 & 8,28 \\
\hline $3 p_{1 / 2}$ & 7,679 & 9,91 & 7,49 & 7,38 \\
\hline $2 \mathrm{~g}_{9 / 2}$ & 4,162 & 6,00 & 4,84 & $3,93^{*}$ \\
\hline $1 i_{11 / 2}$ & 2,083 & 5,68 & 0,33 & $3,15^{*}$ \\
\hline $1 \mathrm{j}_{15 / 2}$ & 1,965 & 4,04 & 5,27 & $2,52^{*}$ \\
\hline $3 \mathrm{~d}_{5 / 2}$ & 2,014 & 3,69 & 2,25 & $2,37^{*}$ \\
\hline $4 s_{1 / 2}$ & 1,452 & 2,57 & 1,07 & $1,89^{\circ}$ \\
\hline $2 g_{7 / 2}$ & 1,279 & 2,80 & 0,04 & $1,43^{* \prime}$ \\
\hline $3 \mathrm{~d}_{3 / 2}$ & 0,980 & 2,20 & 0,35 & $1,39^{*}$ \\
\hline
\end{tabular}


Tabel 3. Hasil perhitungan aras-aras tenaga partikel-tunggal dan lubang-tunggal proton, dinyatakan dengan $-E$ dalam satuan $\mathrm{MeV}$

\begin{tabular}{|c|c|c|c|c|c|c|c|c|c|}
\hline \multirow[t]{2}{*}{ Aras } & \multirow{2}{*}{$\begin{array}{c}\text { Fayans } \\
\text { dkk. }\end{array}$} & \multicolumn{2}{|c|}{ Woods-Saxon } & \multirow[t]{2}{*}{ Eksp. } & \multirow[t]{2}{*}{ Aras } & \multirow{2}{*}{$\begin{array}{c}\text { Fayans } \\
\text { dkk. }\end{array}$} & \multirow{2}{*}{$\begin{array}{l}\text { Woods- } \\
\text { Saxon }\end{array}$} & \multirow{2}{*}{$\begin{array}{l}\text { Eksp. } \\
\text { Baru }\end{array}$} & \\
\hline & & Lama & Baru & & & & & & \\
\hline $1 g_{7 / 2}$ & 11,280 & 10,17 & 10,35 & $1 g_{\pi / 2}$ & $1 \mathrm{~h}_{9 / 2}$ & 3,799 & 2,65 & 3,10 & $1 \mathrm{~h}_{9 / 2}$ \\
\hline $2 \mathrm{~d}_{5 / 2}$ & 9,842 & 7,89 & 11,27 & $2 d_{5 / 2}$ & $2 \mathrm{f}_{7 / 2}$ & 3,144 & 1,01 & 5,58 & $2 \mathrm{f}_{7 / 2}$ \\
\hline $1 h_{1 / 2}$ & 8.787 & 6,75 & 12,65 & $1 \mathrm{~h}_{11 / 2}$ & $1 i_{13 / 2}$ & 2,005 & 0,02 & 7,18 & $1 i_{13 / 2}$ \\
\hline $2 d_{3 / 2}$ & 8,472 & 6,44 & 8,62 & $2 \mathrm{~d}_{3 / 2}$ & $2 f_{5 / 2}$ & 1,225 & 0,00 & 2,08 & $2 \mathrm{f}_{5 / 2}$ \\
\hline $3 s_{1 / 2}$ & 7,691 & 5,68 & 8,83 & $3 s_{1 / 2}$ & $3 p_{3 / 2}$ & 0,350 & 0,00 & 2,99 & $3 p_{3 / 2}$ \\
\hline
\end{tabular}

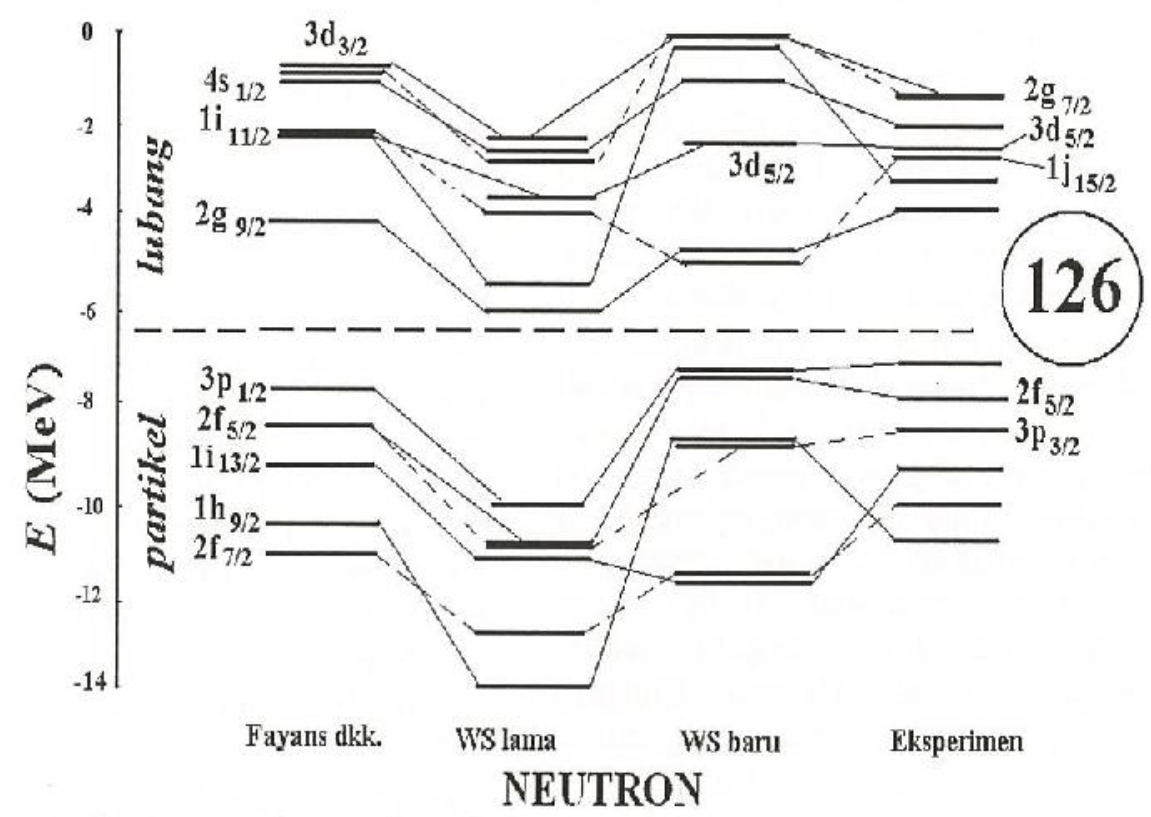

Gambar 1. Spektrum Tenaga Partikel-Tunggal Dan Lubang-Tunggal Neutron dalam Inti ${ }^{208} \mathrm{~Pb}$

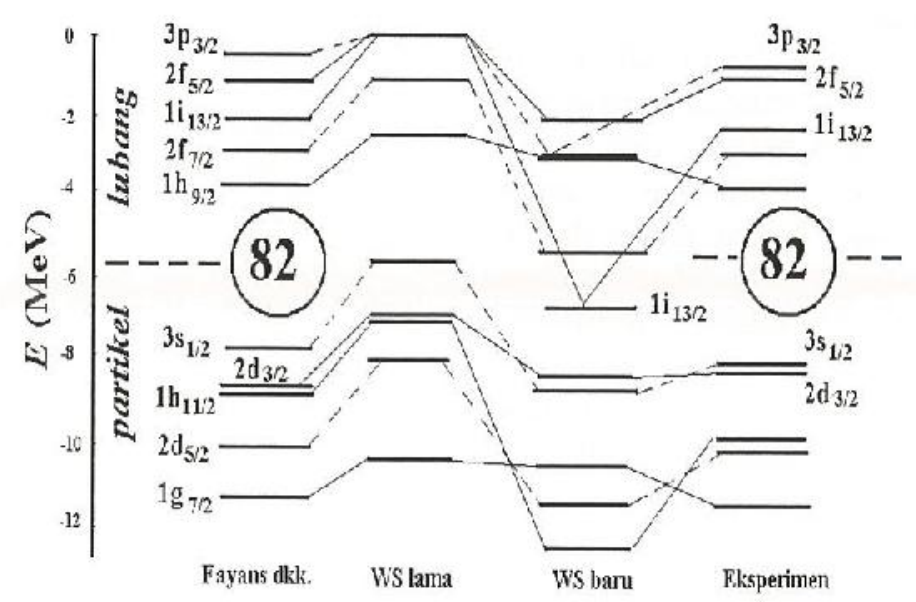

PROTON

Gambar 2. Spektrum Tcnaga Partikel-Tunggal Dan Lubang-Tunggal Proton Dalam Inti ${ }^{208} \mathrm{~Pb}$ 
Dalam hal struktur aras tenaga, hasil perhitungan dengan ketiga metode menunjukkan kesalahan-kesalahan urutan aras tenaga. Lntuk neutron, perhitungan Fayans dkk. menunjukkan tiga kesalahan urutan $\left(\mathrm{Ih}_{9,2}\right.$ dengan $2 \mathrm{f}_{7 / 2}$ terbalik, $2 \mathrm{f}_{5 / 2}$ dengan $3 \mathrm{p}_{3 / 2}$ berimpit, $1 j_{15 / 2}$ dengan $3 \mathrm{~d}_{5 / 2}$ terbalik), sedangkan perhitungan dengan potensial Woods-Saxon parametrisasi baru lebih banyak menunjukkan kesalahan urutan bahkan jika dibandingkan dengan potensial Woods-Saxon parametrisasi lama. Perhitungan dengan potensial WoodsSaxon parametrisasi baru untuk neutron memberikan empat kesalahan urutan $\left(1 h_{g / 2}\right.$ dengan $2 f_{7 / 2}, 2 f_{7 / 2}$ dengan $1 i_{13 / 2}, i_{1 / 12}$ dengan $\mathrm{lj}_{15 / 2}, \quad 2 \mathrm{~g}_{7 / 2}$ dengan $3 \mathrm{~d}_{3 / 2}$, semua terbalik), padahal dengan parametrisasi lama hanya dijumpai satu kesalahan urutan $\left(4 \mathrm{~s}_{1 / 2}\right.$ terbalik dengan $2 g_{7 / 2}$ ). Keadaannya lebih parah lagi untuk proton: perhitungan Fayans dkk. sama sekali tidak memberikan urutan kesalahan, potensial Woods-Saxon parametrisasi lama hanya memberikan satu kesalahan urutan ( $2 \mathrm{f}_{5,2}$ terbalik dengan $3 p_{3 / 2}$ ), namun potensial Woods-Saxon parametrisasi baru justru menunjukkan enam kesalahan urutan (terbalik) yang melibatkan semua aras tenaga yang dikaji (baik partikel maupun lubang). Walaupun demikian ternyata potensial Woods-Saxon parametrisasi baru lebih unggul dalam mendeskripsikan daerah kontinu (lubang) dibandingkan parametrisasi lama, sebagaimana terlihat dari adanya dua aras lubang-tunggal proton yang mempunyai tenaga sama dengan nol (ini bisa berarti tenaganya positif jika digunakan batas atas positif untuk tebakan awal eigennilai tenaga).

Dapat disimpulkan bahwa dalam hal struktur aras tenaga ketelitian perhitungan Fayans dkk. lebih baik daripada hasil perhitungan dengan metode Woods-Saxon, terutama dengan parametrisasi baru. Tabel 4 menyajikan deviasi $r m s$ tenaga partikel-tunggal dan lubang-tunggal hasil perhitungan terhadap nilai eksperimental, dan terlihat jelas bahwa hasil perhitungan Fayans dkk. jauh lebih teliti dari hasil perhitungan menggunakan potensial WoodsSaxon, baik dengan parametrisasi lama maupun baru. Hal ini berlaku untuk semua aras tenaga yang ditinjau (partikel neutron, lubang neutron, partikel proton, lubang proton, dan gabungan aras partikel/lubang).
Tabel 4. Deviasi rms tenaga hasil perhitungan terhadap nilai cksperimental dalam satuan $\mathrm{MeV}$

\begin{tabular}{cccc}
\hline & Fayans & \multicolumn{2}{c}{ Woods-Saxon } \\
\cline { 3 - 4 } Aras & dkk. & Lama & Baru \\
\hline n partikel & 0,427 & 1,902 & 1,097 \\
p partikel & 0,234 & 1,462 & 1,232 \\
n lubang & 0,393 & 1,168 & 1,242 \\
p lubang & 0,165 & 1,030 & 1,993 \\
n & 0,580 & 2,232 & 1,657 \\
(partikel+lubang) & & & \\
p & & & \\
(partikel-lubang) & 0,286 & 1,789 & 2,343 \\
\hline
\end{tabular}

Tabel 4 menunjukkan bahwa dibandingkan parametrisasi lama, parametrisasi baru potensial Woods-Saxon berhasil meningkatkan ketelitian untuk aras-aras partikel baik untuk neutron maupun proton, namun yang sebaliknya justru terjadi untuk aras-aras lubang (parametrisasi lama lebih teliti daripada parametrisasi baru). Jika gabungan semua aras partikel dan lubang dikaji, diperoleh kesimpulan yang membingungkan tentang mana yang lebih teliti, karena parametrisasi baru lebih teliti daripada parametrisasi lama untuk neutron namun sebaliknya untuk proton, parametrisasi lama justru lebih teliti daripada parametrisasi baru. Sebuah faktor yang boleh jadi perlu diperhatikan adalah koreksi pusat massa Pers. (9) yang dalam kajian ini diabaikan.

\section{KESIMPULAN}

Dibandingkan parametrisasi lama yang dikaji di sini, parametrisasi baru potensial WoodsSaxon berhasil meningkatkan ketelitian deviasi rms tenaga terhadap eksperimen hanya sejauh menyangkut deviasi $r m s$ tenaga partikcltunggal saja, namun gagal untuk deviasi rms tenaga lubang-tunggal. Dalam hal struktur aras tenaga, parametrisasi baru potensial WoodsSaxon justru menunjukkan lebih banyak kesalahan urutan aras daripada parametrisasi lama. Dalam semua aspek, baik parametrisasi lama maupun parametrisasi baru potensial Woods-Saxon masih kalah teliti dibandingkan metode perhitungan swakonsisten terbaik oleh Fayans dkk. Untuk kajian selanjutnya dapat 
diperhitungkan adanya koreksi pusat massa untuk penggunaan di daerah kontinu.

\section{DAFTAR PUSTAKA}

1. Ring, P., Schuck, P., "The Nuclear ManyBody Problem", Springer, Berlin (2000) 36-50.

2. Mayer, M.G., Phys. Rev. 75 (1949)1969.

3. Brown, B.A., Wildenthal, B., Ann. Rev. Nucl. Part. Sci. 38 (1988) 29.

4. Brown, B.A., Prog. Part. Nucl. Phys. 47 (2001) 517.

5. Woods, R.D., Saxon, D.S., "Diffuse Surface Optical Model for NucleonNuclei Scattering", Phys. Rev. 95 (1954) 577.

6. López-Quelle, M., Van Giai, N., Marcos, S., Savushkin, L., Phys. Rev. C6106 (2000) 4321.

7. Bernardos, P., Fomenko, V. N., Van Giai, N., López-Quelle, M., Marcos, S., Niembro, R., Savushkin, L. N., Phys. Rev. C48 (1993) 2665.

8. Oktova, R., 'Perhitungan aras-aras tenaga partikel-tunggal inti bola dalam ruang koordinat", Jurnal Forum MIPA 5 (1) (2007), 1.

9. Oktova, R., "Perhitungan Aras-Aras Tenaga Partikel-Tunggal Inti $208 \mathrm{~Pb}$ dengan Potensial Woods-Saxon"
(Prosiding Seminar Nasional Sains \& Pendidikan Sains V, 10 Juni 2010), FSM UKSW Salatiga (2010) 304.

10. Shlomo, S., Bertsch, G., Nucl. Phys. A243 (1975) 507.

11. Bertsch, G., "The Random Phase Aproximation for collective excitations", in LANGANKE K., MARLHN J.A., KOONIN S.E. (editors). Computational Nuclear Physics 1: Nuclear Structure, Chapter 4, New York : Springer-Verlag (1991) 75-87.

12. Schwierz, N, Wiedenhöver, I., Volya, A., "Parameterization of the Woods-Saxon Potential for Shell-Model Calculations", arXiv:0709.3525 [nucl-th] 21 Sept. 2007.

13. Martin, M.J., Nucl. Data Sheects for $A=209$, Nucl. Data Sheeets 63 (1991) 723 .

14. Schmorak, M.R., Nucl. Data Sheeets for $A=207$, Nucl. Data Sheeets 43 (1984) 383.

15. Thijssen, J.M., "Computational Physics". Cambridge University Press (1999).

16. Oktova, R., "Perhitungan Momen Kelembaman Inti Genap-Genap dengan Model Superfluida." Tesis S2 Fisika. Yogyakarta : Program Pascasarjana UGM (1996) $42-54$.

17. Fayans, S. A.,Trykov, E. L.,Zawischa. D., Influence of effective spin-orbit interaction on the collective states of nuclei. Nucl Phys. A568 (1994) $523-543$. 